\title{
Vitamin D Deficiency Induced Hypocalcemia as a Leading Cause of Dilated Cardiomyopathy: A Rare Report
} \author{
Moghadam ${ }^{4 *}$ \\ ${ }^{1}$ Medical doctor, Growth and Development Research Center, Tehran University of Medical Sciences, Tehran, Iran \\ ${ }^{2}$ Medical Student, Tehran University of Medical Sciences, Tehran, Iran \\ ${ }^{3}$ Medical doctor, Growth and Development Research Center, Tehran University of Medical Sciences, Tehran, Iran \\ ${ }^{4}$ Assistant Professor of Pediatric Cardiology, Tehran University of Medical Science, Iran
}

Amir Salimi ${ }^{1}$, Shakila Meshkat ${ }^{2}$, Parastoo rostami ${ }^{3}$, Azin Ghamari ${ }^{3}$, Helia mojtabavi ${ }^{2}$ and Ehsan Aghaei

*Corresponding author: Ehsan Aghaei Moghadam, Assistant Professor of Pediatric

Received Date: May 21, 2019

Cardiology, University of Medical Science, Tehran, Iran.

Published Date: May 31, 2019

\begin{abstract}
Hypocalcemia is an infrequent and essential reversible cause of Dilated cardiomyopathy, in infant's hypocalcemia is usually due to vitamin D deficiency and often results in high mortality. Beside standard treatment of heart failure, restoration of serum calcium levels with calcium and vitamin D supplementation should be considered. This report describes a 5 months old infant case of dilated cardiomyopathy due to hypocalcemia as a result of vitamin D deficiency.
\end{abstract}

Key words: Dilated cardiomyopathy; Vitamin D deficiency; Calcium deficiency

\section{Introduction}

Hypocalcemia, a critical metabolic disorder, is associated with musculoskeletal, neurologic and cardiogenic symptoms. It can lead to seizure disorders, heart failure, muscle tremors and fasciculation, muscle cramping, facial rubbing, stiff gait, restlessness, aggression, hypersensitivity, and disorientation [1]. Among which, heart failure and cardiomyopathy are infrequent complications of hypocalcemia in pediatric population with prevalence rate of affecting 3.4-26 cases in million per year [2]. On the other side, pediatric cardiomyopathies are life-treating rare diseases with an incidence of 1.1 to 1.5 per $100^{\prime} 000$. In specific, dilated and hypertrophic cardiomyopathies are frequent, while restrictive non-compaction and mixed cardiomyopathies are uncommon [3] Dilated cardiomyopathy can develop into heart failure with a high mortality and morbidity rate [4]. Hence, hypocalcemia is one of the rare and revocable causes of secondary CMP. By this paper, we aim to cast light on clinical diagnostic and treatment methods of a unique case presentation, a five months old infant with dilated cardiomyopathy and mild left ventricular non compaction due to hypocalcemia.

\section{Case Presentation}

A 5 months old infant presented with convulsion, apnea and cyanosis. Before this episode, he was complaining of coughing and had difficulty in breathing associated with poor feeding and muscle spasms that the clinical examination was normal all through. $\mathrm{He}$ recovered after taking azithromycin and co-amoxiclav antibiotic regimen.

He was delivered preterm due to Premature Rupture of Membranes (PROM) by cesarean section. Apparently, goat milk was the sole component of his diet and he has no history of Multi vitamin nor Vitamin $\mathrm{A}+\mathrm{D}$ consumption.

The anterior fontanel was wide open, no murmur was heard on cardiac examination. Cardiac echocardiography was performed showing diffused LVNC, moderate to severe MR with multiple jets, moderate TR, remarkable decrease in $\mathrm{LV}$ systolic function $(\mathrm{EF}=25 \%)$ with mild decrease of RV systolic function(RV $E F=30$ 35\%), normal PAP and normal PV drainage, without any stenotic lesion or coronary abnormalities. He was admitted to Intensive 
care unit for 30 days. The laboratory data finding were as follows; alkaline phosphatase of $1435 \mathrm{IU} / \mathrm{L}$, calcium was $5 \mathrm{mg} / \mathrm{dL}$, phosphate was $7 \mathrm{mg} / \mathrm{dL}$, BUN was $17 \mathrm{mg} / \mathrm{dL}$, Creatinine was 0.5 , Sodium was $136 \mathrm{mEq} / \mathrm{L}$, Potassium was $5.6 \mathrm{meq} / \mathrm{L}$, uric acid $2.6 \mathrm{mg} / \mathrm{dL}$, Hemoglobin was $10.4 \mathrm{~g} / \mathrm{dL}$, white blood cells were $15.59 \mathrm{~mm} 3$, and platelets were $473,000 \mathrm{~mm} 3$. Electrocardiography showed evidence of $\mathrm{LV}$ enlargement with long numerous R wave from V5 to V6 and 1 and AVL. Chest $x$ ray was compatible with cardiomegaly. A brain ultrasound scan showed no intra- cranial lesion nor abnormal echogenicity.

He was treated with Calcium gluconate $6 \mathrm{cc} / \mathrm{kg}$, Calcicare $0.8 \mathrm{cc} /$ $\mathrm{kg}$, calcitriol $0.05 \mathrm{mg} / \mathrm{kg}$, vitamin D $1000 \mathrm{unit} / \mathrm{kg}$ for 10 days. At the follow-up echocardiography 11 days post treatment mild to moderate TR, mild to moderate MR, improved systolic function $(\mathrm{EF}=58 \%)$, normal PV drainage, NL PAP, no CoA were reported. The biochemical findings on discharge were; calcium $9 \mathrm{mg} / \mathrm{dL}$, phosphate $2.6 \mathrm{mg} / \mathrm{dL}$, BUN $4 \mathrm{mg} / \mathrm{dL}$, creatinine $0.5 \mathrm{mg} / \mathrm{dl}$, Na $135 \mathrm{mEq} / \mathrm{L}, \mathrm{K} 4.3 \mathrm{meq} / \mathrm{L}$. The biochemical findings at different treatment stages is well illustrated at the (Table 1).

Table 1: Biochemical findings at different treatment stages.

\begin{tabular}{|c|c|c|c|}
\hline Biochemical Test & Normal Range & Onset & Discharge \\
\hline Calcium $(\mathrm{mg} / \mathrm{dl})$ & $8.6-10.3$ & 5 & 9 \\
\hline Phosphate $(\mathrm{mg} / \mathrm{dl})$ & $3.1-6$ & 7 & 3.8 \\
\hline Magnesium $(\mathrm{mg} / \mathrm{dl})$ & $1.5-2.3$ & 1.4 & 2.6 \\
\hline 25hydroxy vit D (ng/ml) & $>30$ & $<8$ & 40 \\
\hline
\end{tabular}

\section{Discussion}

Pediatric Dilated Cardiomyopathies (DCM) defined as a measured $\mathrm{LV}$ ejection fraction $<45 \%$, may rise from innumerable causes as, coronary artery abnormalities, tachyarrhythmia, exposure to infection or toxins, infectious diseases, metabolic disorders, endocrine diseases, nutritional deficiencies, electrolyte and renal anomalies, deposition diseases, autoimmune disorders, and lastly systemic disorders. However, myocarditis is responsible for more than $50 \%$ of known cases of DCM. Infants with DCM often present with symptoms of HF such as tachypnea, dyspnea, tachycardia, and feeding difficulty [3,5].

In conclusion, hypocalcemia is an infrequent and essential reversible cause of DCM. The pathophysiology of hypocalcemia DCM is quite doubtful, even though the physiologic role of calcium on muscle contraction is well recognized, cardiac contractions can be directly affected by calcium through the excitation-contraction coupling [6]. Beside heart failure, elevated cardiac enzyme and STsegment changes in ECG which can come with acute myocardial infarction may also rise from hypocalcemia [7]. Hypocalcemia cardiomyopathy is unmanageable with cardiac failure treatment individually but responses to calcium replacement [8].

Considering that goat milk was a sole component in our patient diet, and he had no history of vitamins consumption. Each $120 \mathrm{cc}$ of goat milk contains about 29 units of vitamin D, while an infant needs 400 units of vitamin D per-day for their growth [9], hence vitamin D deficiency can be developed if goat milk is not fortified with vitamin D. In conclusion, our patient developed dilated cardiomyopathy due to hypocalcemia. Significant recovery was evident in echocardiographic study after intravenous and oral calcium administration.

\section{Acknowledgement}

None.

\section{Conflict of Interest}

No conflict of interest.

\section{References}

1. De Brito Galvão JF, Schenck PA, Chew DJ (2017) A Quick Reference on Hypocalcemia. Vet Clin North Am Small Anim Pract 47(2): 249-56.

2. Daubeney PE, Nugent AW, Chondros P, Carlin JB, Colan SD, et al. (2006) Clinical features and outcomes of childhood dilated cardiomyopathy: results from a national population-based study. Circulation 114(24): 2671-2678.

3. Lee TM, Hsu DT, Kantor P, Towbin JA, Ware SM, et al. (2017) Pediatric cardiomyopathies. Circ Res 121(7): 855-873.

4. Lipshultz SE, Cochran TR, Briston DA, Brown SR, Sambatakos PJ, et al. (2013) Pediatric cardiomyopathies: causes, epidemiology, clinical course, preventive strategies and therapies. Future Cardiol 9(6): 817-48.

5. Soares P, Rocha G, Pissarra S, Soares H, Flor De Lima F, et al. (2017) Neonatal dilated cardiomyopathy. Rev Port Cardiol 36(3): 201-214.

6. Bansal B, Bansal M, Bajpai P, Garewal HK (2014) Hypocalcemic cardiomyopathy-different mechanisms in adult and pediatric cases. J Clin Endocrinol Metab 99(8): 2627-32.

7. Rallidis LS, Gregoropoulos PP, Papasteriadis EG (1997) A case of severe hypocalcemia mimicking myocardial infarction. Int J Cardiol 61(1): 8991.

8. Debmalya Sanyal, Moutusi Raychaudhuri (2013) Infants with dilated cardiomyopathy and hypocalcemia. Indian J Endocrinol Metab 17(Suppl 1): S221-S223.

9. Martin CR, Ling PR, Blackburn GL (2016) Review of Infant Feeding: Key Features of Breast Milk and Infant Formula. Nutrients 8(5): E279. 